\title{
Tracé du train à grande vitesse « TGV Nord »
}

\section{(2) OpenEdition \\ Journals}

Édition électronique

URL : http://journals.openedition.org/adlfi/10153

ISSN : 2114-0502

Éditeur

Ministère de la culture

Référence électronique

"Tracé du train à grande vitesse «TGV Nord » , ADLFI. Archéologie de la France - Informations [En ligne], Nord-Pas-de-Calais, mis en ligne le 01 mars 1997, consulté le 03 mai 2019. URL : http:// journals.openedition.org/adlfi/10153

Ce document a été généré automatiquement le 3 mai 2019.

(C) Ministère de la Culture et de la Communication, CNRS 


\section{Tracé du train à grande vitesse «TGV Nord»}

1 Le tracé du Train à Grande Vitesse (TGV) traverse une grande partie de la région Nord-Pasde-Calais (Fig. $\mathrm{n}^{\circ} 1$ : Localisation des zones fouillées), sur une largeur moyenne de $50 \mathrm{~m}$ (hors ouvrages annexes). En raison de sa longueur, le tracé a été divisé en deux sections :Artois $(113 \mathrm{~km})$ et Flandres $(92 \mathrm{~km})$, chacune prospectée de septembre 1988 à juin 1989 inclus. La phase de prospection s'est déroulée en quatre périodes :

2 - la première période (septembre 1988) a été consacrée à la consultation d'archives et aux recherches bibliographiques, essentiellement dans le fichier de la carte archéologique des Directions régionales des Antiquités. Sept sites seulement étaient antérieurement connus sur la section Artois ; on ne connaissait pas de site dans les Flandres, exceptés les abords de la cité gallo-romaine de Cassel ;

3 - la suivante (octobre à décembre1988) a concerné la prospection pédestre :le ramassage de surface puis l'examen des microtopographies, une démarche surtout mise en oeuvre en Flandres, pays plat et humide où les sites fossoyés sont nombreux. Ainsi, vingt-sept indices ont été découverts en Artois et trente-et-un en Flandres (section dont la moitié des sites relève des époques médiévale et moderne). La prospection au sol a été complétée par quelques survols qui ont seulement permis de préciser l'implantation de sites connus;

4 - durant la troisième période (janvier, février et avril 1989), des sondages furent réalisés à l'aide de moyens mécaniques : d'une part, des sondages de vérification et de délimitation, ouverts sur les sites repérés par prospection pédestre; d'autre part, des sondages de prospection proprement dits sur les secteurs présumés favorables à l'implantation humaine (les vallées en Artois et les éminences dans la plaine flamande). Ces sondages ont consisté en une tranchée de décapage unique, large d'environ $2 \mathrm{~m}$, ouverte dans l'axe médian de l'emprise ;

5 - enfin, la dernière période (mars, mai et juin 1989) fut consacrée au rapport de synthèse. 


\section{ANNEXES}

Fig. $n^{\circ} 1$ : Localisation des zones fouillées

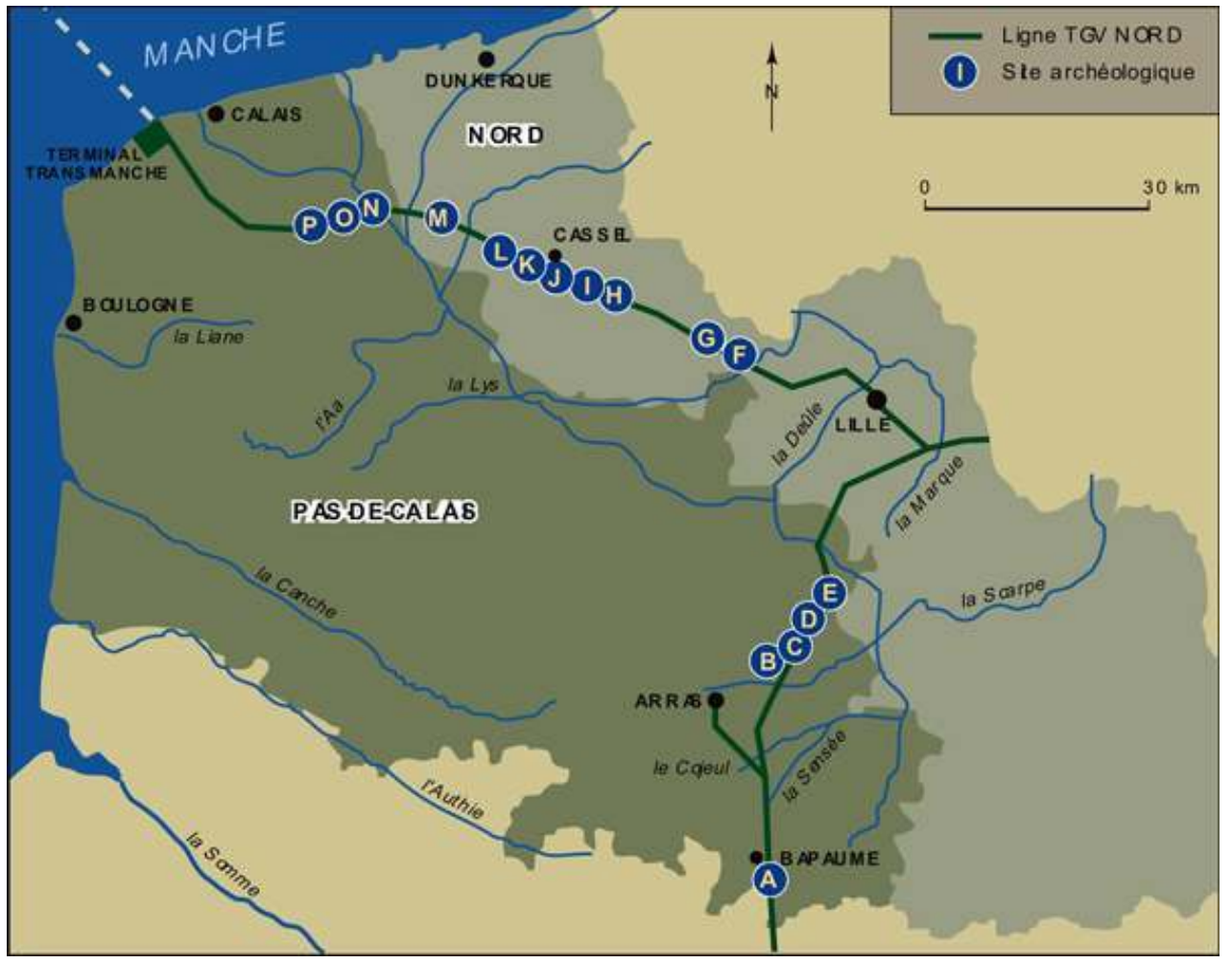

GI, 1997 - CNRS editions, 1998 (1997)

INDEX

Index chronologique : Antiquité romaine, Moyen Âge*, Paléolithique, Protohistoire 